\title{
Multi-Component Adsorption of Benzene, Toluene, Ethylbenzene, and Xylene from Aqueous Solutions by Montmorillonite Modified with Tetradecyl Trimethyl Ammonium Bromide
}

\author{
H. Nourmoradi, ${ }^{1,2}$ Mehdi Khiadani, ${ }^{1,3}$ and M. Nikaeen ${ }^{1}$ \\ ${ }^{1}$ Department of Environmental Health Engineering, Environment Research Center, School of Health, \\ Isfahan University of Medical Sciences, Isfahan, Iran \\ ${ }^{2}$ Department of Environmental Health Engineering, School of Health, Ilam University of Medical Sciences, Ilam, Iran \\ ${ }^{3}$ School of Engineering, Edith Cowan University, Joondalup, WA, Australia
}

Correspondence should be addressed to Mehdi Khiadani; m.khiadani@ecu.edu.au

Received 12 February 2012; Revised 17 May 2012; Accepted 21 May 2012

Academic Editor: Annalisa De Girolamo

Copyright (C) 2013 H. Nourmoradi et al. This is an open access article distributed under the Creative Commons Attribution License, which permits unrestricted use, distribution, and reproduction in any medium, provided the original work is properly cited.

\begin{abstract}
Multicomponent adsorption of benzene, toluene, ethylbenzene, and xylene (BTEX) was assessed in aqueous solutions by montmorillonite modified with tetradecyl trimethyl ammonium bromide (TTAB-Mt). Batch experiments were conducted to determine the influences of parameters including loading rates of surfactant, contact time, $\mathrm{pH}$, adsorbate concentration, and temperature on the adsorption efficiency. Scanning electron microscope (SEM) and X-ray diffractometer (XRD) were used to determine the adsorbent properties. Results showed that the modification of the adsorbent via the surfactant causes structural changes of the adsorbent. It was found that the optimum adsorption condition achieves with the surfactant loading rate of $200 \%$ of the cation exchange capacity (CEC) of the adsorbent for a period of $24 \mathrm{~h}$. The sorption of BTEX by TTAB-Mt was in the order of $\mathrm{B}<\mathrm{T}<\mathrm{E}<\mathrm{X}$. The experimental data were fitted by many kinetic and isotherm models. The results also showed that the pseudo-second-order kinetic model and Freundlich isotherm model could, respectively, be fitted to the experimental data better than other available kinetic and isotherm models. The thermodynamic study indicated that the sorption of BTEX with TTAB-Mt was achieved spontaneously and the adsorption process was endothermic as well as physical in nature. The regeneration results of the adsorbent also showed that the adsorption capacity of adsorbent after one use was $51 \%$ to $70 \%$ of original TTAB-Mt.
\end{abstract}

\section{Introduction}

Petroleum hydrocarbons such as BTEX (benzene, toluene, ethylbenzenem and xylene) are one of the most common pollutants that cause environmental pollution [1]. These compounds are volatile monoaromatic hydrocarbons that are present in petroleum, gasoline, and industrial solvents [2]. BTEX has been introduced in the environment through petrochemical wastewater, fuel leakage from storage tanks and transportation $[3,4]$.

BTEX has harmful effects on the human health that lead to cancer, mucosal membranes irritation, impairment of the central nervous system, and liver and kidney disruption $[5,6]$. Due to these adverse health effects, removal of BTEX from water and wastewater is essential. Chemical oxidation, biological treatment, air stripping, and adsorption have been successfully carried out for the removal of BTEX from aqueous solutions [5]. Adsorption process is one of the prominent treatment options for the removal of these pollutants from the aqueous mediums because it is possible to recover the adsorbent and adsorbate [4, 7]. Many adsorbents including activated carbon $[8,9]$, carbon nanotube $[2,10]$, macroreticular resins [7], diatomite $[1,4,5]$, and organoclay [11-17] have been used for adsorption of BTEX from aqueous solutions. Activated carbon is the most common material used extensively as an adsorbent for this purpose [9]; however, it is expensive and the regeneration cost is high $[8,18]$.

Clay, because of its high surface area, low cost, being eco-friendly, and nontoxicity, has a good efficacy in the 
adsorption of various pollutants in aqueous solutions [1922]. Raw clay, due to the hydration of inorganic cations in its active sites, has a hydrophilic property. Therefore, it is ineffective for the removal of nonpolar nonionic organic compounds such as BTEX. Hence, the modification of clay by a surfactant, especially the cationic type, shifts it from the hydrophilic nature to the organophilic one [23]. Many studies have been conducted by other researchers for the removal of BTEX with clay modified by cationic surfactants [11-17]. However, to the authors knowledge modification of clay with tetradecyl trimethyl ammonium bromide (TTAB) as a cationic surfactant has not been investigated. In this study montmorillonite, a type of clay, was modified by TTAB and used to remove BTEX from aqueous solution.

\section{Materials and Methods}

\subsection{Materials}

The montmorillonite (Mt) was purchased from Laviosa Co. (Italy). The cationic surfactant, tetradecyl trimethyl ammonium bromide (TTAB), $\left(\mathrm{CH}_{3}\left(\mathrm{CH}_{2}\right)_{13} \mathrm{~N}(\mathrm{Br})\left(\mathrm{CH}_{3}\right)_{3}\right.$ with $\geq 99 \%$ purity), was provided by Aldrich Co. Benzene ( $\geq 99 \%)$, toluene $(99.5 \%)$, ethylbenzene $(\geq 99 \%)$, and xylene (99.5\%) were purchased from Merck Co. The BTEX standard solution $(400 \mathrm{mg} / \mathrm{L} \mathrm{BTEX}=100 \mathrm{mg} / \mathrm{L}$ benzene $+100 \mathrm{mg} / \mathrm{L}$ toluene $+100 \mathrm{mg} / \mathrm{L}$ ethylbenzene $+100 \mathrm{mg} / \mathrm{L}$ xylene) was prepared in distilled water and kept at $4^{\circ} \mathrm{C}$. The stock solution was diluted by distilled water as working solutions. Other chemicals used were of analytical grade.

2.2. Purification and Modification of the Adsorbent. In order to purify the clay, $30 \mathrm{~g}$ of the raw Mt was dissolved in $1 \mathrm{~L}$ distilled water and mixed with a mechanical stirrer $(600 \mathrm{rpm}$ for $24 \mathrm{~h})$ at room temperature $\left(25^{\circ} \mathrm{C}\right)$. The Mt impurities such as iron oxide and silica, because of higher density, were precipitated in the tube using a centrifuge rotating at $6000 \mathrm{rpm}$ for $15 \mathrm{~min}$ [24]. The impurities were removed from the solution and high-purity $\mathrm{Mt}$ was then dried $\left(110^{\circ} \mathrm{C}\right.$ for $\left.24 \mathrm{~h}\right)$, ground and sieved to a size of less than $125 \mu \mathrm{m}$. The cation exchange capacity of the raw Mt after purification was increased from 86 to $108 \mathrm{meq} / 100 \mathrm{~g}$ clay. The $\mathrm{Na}$-montmorillonite (NaMt) was prepared by mixing the high purity Mt with $1 \mathrm{~N}$ $\mathrm{NaCl}$ using a mechanical stirrer $(600 \mathrm{rpm}$ for $24 \mathrm{~h}$ ) at room temperature of $25^{\circ} \mathrm{C}$. The Na-Mt was then separated and washed four times with distilled water to make sure all chloride was removed as confirmed by $1 \mathrm{M} \mathrm{AgNO}_{3}$ [25].

The amount of $5 \mathrm{~g}$ of dried and pulverized Na-Mt was dissolved in $100 \mathrm{~mL}$ distilled water and modified with TTAB of $0.363 \mathrm{~g}, 0.908 \mathrm{~g}, 1.271 \mathrm{~g}, 1.816 \mathrm{~g}, 2.179 \mathrm{~g}, 2.725 \mathrm{~g}, 3.633 \mathrm{~g}$, $5.449 \mathrm{~g}$, and $7.266 \mathrm{~g}$, respectively, equal to $0.2,0.5,0.7,1,1.2$, $1.5,2,3$, and 4 CEC of the clay. The suspensions were mixed by mechanical stirrer $(600 \mathrm{rpm}$ for $24 \mathrm{~h})$, at $60^{\circ} \mathrm{C}$. The TTABMt was then centrifuged, washed (four times), dried $\left(60^{\circ} \mathrm{C}\right.$ for $24 \mathrm{~h}$ ) and ground to $<125 \mu \mathrm{m}$ for subsequent use.

2.3. Characterization and Analysis. The surface area of the Na-Mt and TTAB-Mt was measured by Sear's method [26].
The cation exchange capacity of the adsorbent was determined by ammonium acetate procedure [27]. The morphology of the raw and modified adsorbent was specified by a scanning electron microscope (Seron, AIS-2100, Republic of Korea). The FTIR spectra and the composition of the raw and modified adsorbents were characterized using a FTIR spectrophotometer (JASCO, FT/IR-6300, Japan) in the range of $400-4000 \mathrm{~cm}^{-1}$ and X-ray diffractometer (Bruker, D8ADVANCE, Germany) using Ni-filtered $\mathrm{Cu} \mathrm{K} \alpha \alpha$ radiation $(1.5406 \AA)$, respectively. The concentration of BTEX in the solutions was measured by gas chromatography (Agilent GC, 7890A) equipped with flame ionization detector (GCFID). The GC-FID method for determination of BTEX was optimized as follows:

(i) Sampling method: head space;

(ii) Injected sample volume: $250 \mu \mathrm{L}$;

(iii) Carrier gas: helium (purity 99.995\%) with flow rate of $1.11 \mathrm{~mL} / \mathrm{min}$;

(iv) Fuel gas: $\mathrm{H}_{2}$ with flow rate of $30 \mathrm{~mL} / \mathrm{min}$;

(v) GC column characteristic: Agilent 19091S-433: $30 \mathrm{~m}$ $\times 250 \mu \mathrm{m} \times 0.25 \mu \mathrm{m}$;

(vi) Detector temperature: $250^{\circ} \mathrm{C}$;

(vii) Oven temperature: $36^{\circ} \mathrm{C}$ for $1 \mathrm{~min}$ then increased to $90^{\circ} \mathrm{C}$ at a rate of $10^{\circ} \mathrm{C} / \mathrm{min}$ with a subsequent increase to $150^{\circ} \mathrm{C}$ at rate of $25^{\circ} \mathrm{C} / \mathrm{min}$ for a period of $6 \mathrm{~min}$ (total run time: $14.8 \mathrm{~min}$ ).

2.4. Adsorption Experiments. All adsorption experiments (except the one for the effects of temperature on the adsorption) were carried out at room temperature $\left(25^{\circ} \mathrm{C}\right)$ with $100 \mathrm{~mL}$ of BTEX solution into a $200 \mathrm{~mL}$ conical flask (with air tight cape) and shaken at $250 \mathrm{rpm}$ for $24 \mathrm{~h}$. After this, the suspensions were centrifuged (6000 rpm for $15 \mathrm{~min}$ ) and the clear supernatant was analyzed for BTEX by GC-FID. Blank samples (BTEX solution without the adsorbent) were also used to determine the value of BTEX volatilization. The BTEX loss due to the volatilization was estimated to be in the range of $2-8 \%$. The experimental data were corrected to account for volatilize BTEX. The adsorbent capacity of the TTAB-Mt for BTEX uptake was determined from

$$
q_{e}=\frac{\left(C_{0}-C_{e}\right) V}{m},
$$

where $q_{e}(\mathrm{mg} / \mathrm{g})$ is the adsorption capacity of the adsorbent, $C_{o}(\mathrm{mg} / \mathrm{L})$ is the initial concentration of the adsorbate, $C_{e}$ $(\mathrm{mg} / \mathrm{L})$ is the equilibrium concentration of the adsorbate in the solution, $m(\mathrm{~g})$ is the mass of the adsorbent, and $V(\mathrm{~L})$ is the volume of the solution.

2.4.1. Effect of the Surfactant Loading Rate. The effect of various loading rates of the surfactant onto the clay $(0.2,0.5$, $0.7,1,1.2,1.5,2,3$, and 4 CEC of the clay) for BTEX removal was determined using $100 \mathrm{~mL}$ of a solution containing $0.5 \mathrm{~g}$ clay and $150 \mathrm{mg} / \mathrm{L}$ BTEX. The suspensions were mixed, centrifuged, and analyzed for the organic pollutants by GCFID. 
2.4.2. Effect of Contact Time and $p H$. The effect of contact time on the adsorption was carried out using $100 \mathrm{~mL}$ of a solution containing $0.5 \mathrm{~g}$ adsorbent and $150 \mathrm{mg} / \mathrm{L}$ BTEX at various contact times $(0.5,1,2,3,4,5,8,12,16,24 \mathrm{~h})$. The $\mathrm{pH}$ experiments were also conducted with optimum contact time at various $\mathrm{pH}$ values ranging from 4 to 12 . The adjustment of the $\mathrm{pH}$ solution was carried out with $0.1 \mathrm{M} \mathrm{HCl}$ and $0.1 \mathrm{M}$ $\mathrm{NaOH}$ to the desired value.

2.4.3. Effect of Adsorbate Concentration and Temperature. In many industrial wastewaters the concentration of BTEX varies between 20 to $200 \mathrm{mg} / \mathrm{L}$ [2]. Hence, the effect of initial BTEX concentrations $(10,25,50,75,100,125,150$, and $200 \mathrm{mg} / \mathrm{L}$ ) on the adsorption efficiency was evaluated at the optimum contact time and $\mathrm{pH}$ at $25^{\circ} \mathrm{C}$. The effect of various temperatures $\left(10,20,30,40^{\circ} \mathrm{C}\right)$ on the adsorption at the optimum contact time and $\mathrm{pH}$ was also performed.

2.4.4. Regeneration of BTEX Saturated TTAB-Mt. The regeneration experiments were performed by heating. For this, the TTAB-Mt was subjected to the adsorption as follows. Initially $0.5 \mathrm{~g}$ of the adsorbent was equilibrated in $100 \mathrm{~mL}$ of $150 \mathrm{mg} / \mathrm{L}$ BTEX at the optimum contact time and $\mathrm{pH}$ at $25^{\circ} \mathrm{C}$. After mixing, the supernatant was centrifuged and analyzed. The saturated clay was then separated and dried at room temperature for $48 \mathrm{~h}$. The BTEX that saturated TTABMt were then placed in oven at $150^{\circ} \mathrm{C}$ for 5,10 , and $20 \mathrm{~min}$. The adsorption experiments were then conducted using the regenerated adsorbent.

\section{Results and Discussion}

\subsection{Characterization of the Adsorbent}

The physical and chemical characteristics of the adsorbent are presented in Table 1. The SEM images of the Raw-Mt and TTAB-Mt are presented in Figures 1(a) and 1(b). The surface structure of the adsorbent is changed by the modification with TTAB. It can be seen that the surface texture of the Raw-Mt is rough with irregular shapes. However, the surface morphology of the TTAB-Mt is smoother than Raw-Mt. This is due to the fact that the porous surface of Raw-Mt is filled with surfactant. The adsorbent modification by TTAB leads to reduction of the surface area from $32.6 \mathrm{~m}^{2} / \mathrm{g}$ to $26.2 \mathrm{~m}^{2} / \mathrm{g}$ for Raw-Mt and TTAB-Mt, respectively.

Figure 1(c) presents the FT-IR spectrums of the NaMt and TTAB-Mt. The results of infrared spectrum showed that the absorption bands are corresponding to the montmorillonite. As seen in this figure, the absorption band at $3627 \mathrm{~cm}^{-1}$ is assigned to the stretching vibration of ${ }^{-} \mathrm{OH}$ groups, which may be due to the isomorphic substitution in the Raw-Mt tetra- and octa-hedral layers [28]. The wide band at $3436 \mathrm{~cm}^{-1}$ is attributed to $\mathrm{H}_{2} \mathrm{O}$ stretching vibration [18]. The IR band of $1635 \mathrm{~cm}^{-1}$ is also assigned to $\mathrm{Al}$ and $\mathrm{Mg}$ bound water molecules [29]. A broad band at $1037 \mathrm{~cm}^{-1}$ is related to $\mathrm{Si}-\mathrm{O}$ groups stretching vibration, whereas the bands at $525 \mathrm{~cm}^{-1}$ and $468 \mathrm{~cm}^{-1}$ are attributed to Al-O-Si and
TABLE 1: Composition of montmorillonite used in this study.

\begin{tabular}{lc}
\hline Chemical composition (\%) & 60 \\
\hline $\mathrm{SiO}_{2}$ & 20.03 \\
$\mathrm{Al}_{2} \mathrm{O}_{3}$ & 2.31 \\
$\mathrm{Fe}_{2} \mathrm{O}_{3}$ & 3.02 \\
$\mathrm{Na}_{2} \mathrm{O}$ & 4.02 \\
$\mathrm{MgO}$ & 0.05 \\
$\mathrm{P}_{2} \mathrm{O}_{5}$ & 0.13 \\
$\mathrm{~K}_{2} \mathrm{O}$ & 1.46 \\
$\mathrm{CaO}$ & 0.23 \\
$\mathrm{TiO}_{2}$ & 0.03 \\
$\mathrm{MnO}$ & 8.71 \\
$\mathrm{H}_{2} \mathrm{O}$ & \\
\hline Mineralogical analysis (\%) & 98 \\
\hline Montmorillonite & $0.5-1$ \\
Feldspar & $0.5-1$ \\
Quartz & 108 \\
\hline Other & 7.03 \\
\hline CEC (meq/100 g) & \\
Limit of ignition (\%) & \\
\hline
\end{tabular}

$\mathrm{Si}-\mathrm{O}-\mathrm{Si}$ vibrations, respectively [30]. The bands at $2851 \mathrm{~cm}^{-1}$ and $2922 \mathrm{~cm}^{-1}$ in the modified adsorbent are due to $\mathrm{C}-\mathrm{H}$ stretching vibration.

The XRD patterns of Raw-Mt and TTAB-Mt samples are shown in Figure $1(\mathrm{~d})$. The XRD basal spacing $\left(d_{001}\right)$ of the Raw-Mt and TTAB-Mt were found to be $12.10 \AA$ and $18.59 \AA$, respectively. Moreover, increasing the reflection intensity from $21.8 \%$ for Raw-Mt to $100 \%$ for TTAB-Mt showed that the surfactant modification has led to structural changes in the Raw-Mt. The interlamellar expansion in the modified adsorbent may be due to the penetration of TTAB into the layer of Raw-Mt.

3.2. Effect of the Surfactant Loading Rate. The influence of different loading rates of the surfactant onto the adsorbent was also assessed in the removing BTEX from aqueous solution. The results are shown in Figure 2. As can be seen, the sorption capacity $\left(q_{e}\right)$ was increased by increasing the surfactant loading to $200 \%$ of CEC. Ma et al. (2011) reported that the adsorption capacity of HDTMA-bentonite for the anionic dyes (Orange II and Orange G) was increased by increasing the amounts of HDTMA to $200 \%$ of CEC [31]. The sorption capacity was then decreased by increasing the surfactant loading rate, exceeding from $200 \%$ of CEC of the clay. The higher surfactant loading rates, after $200 \%$ of CEC, may have caused to complete occupancy of the internal pores of the adsorbent, resulting in reduced BTEX penetration to these regions. Hence, TTAB-Mt with surfactant loading rate of $200 \%$ CEC was used for the remaining experiments.

3.3. Effect of Contact Time and Adsorption Kinetics. The adsorption data for BTEX uptake by TTAB-Mt are presented 


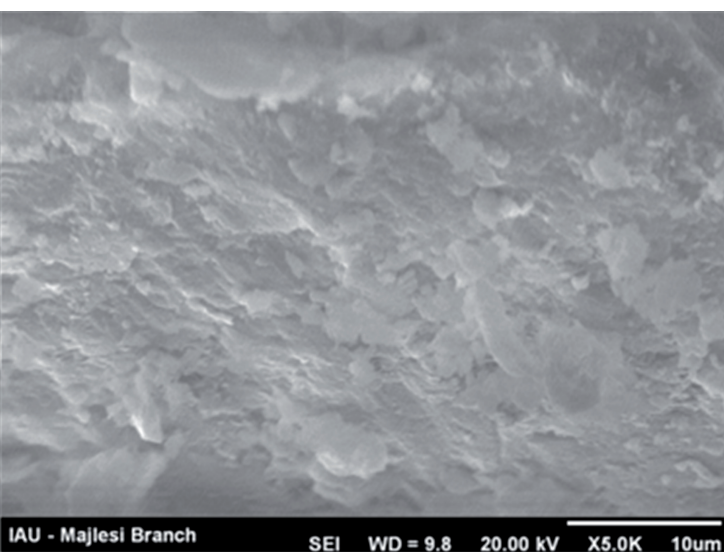

(a)

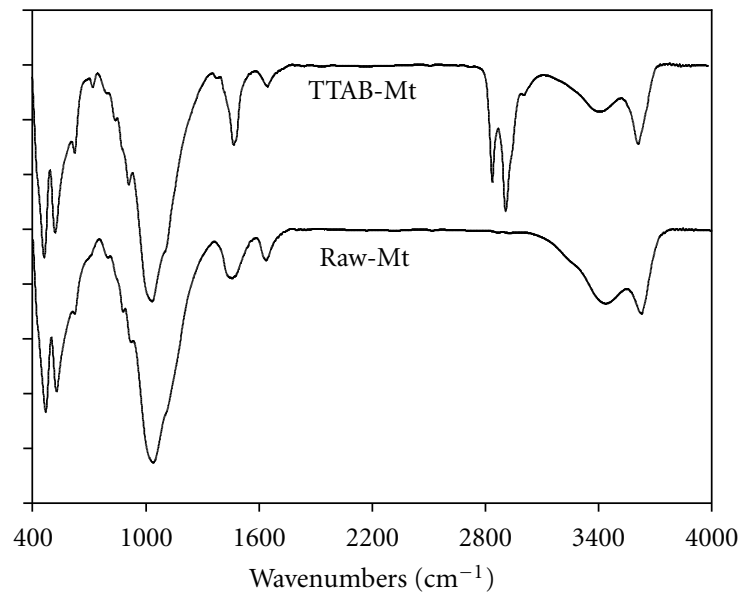

(c)

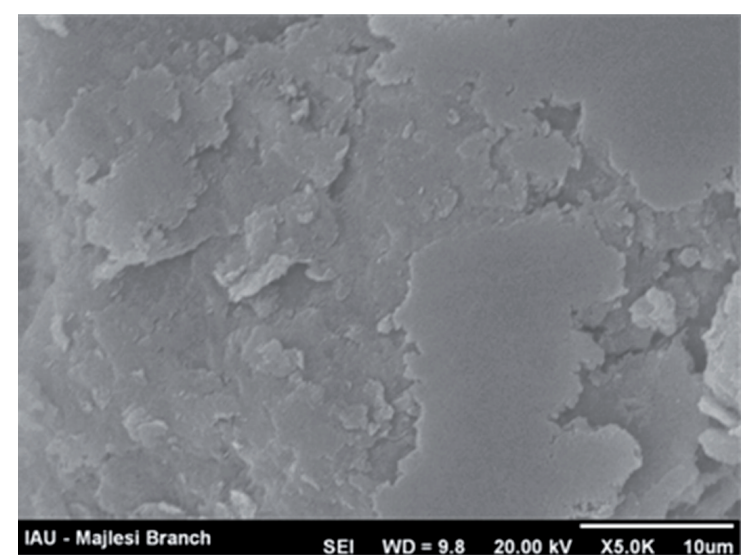

(b)

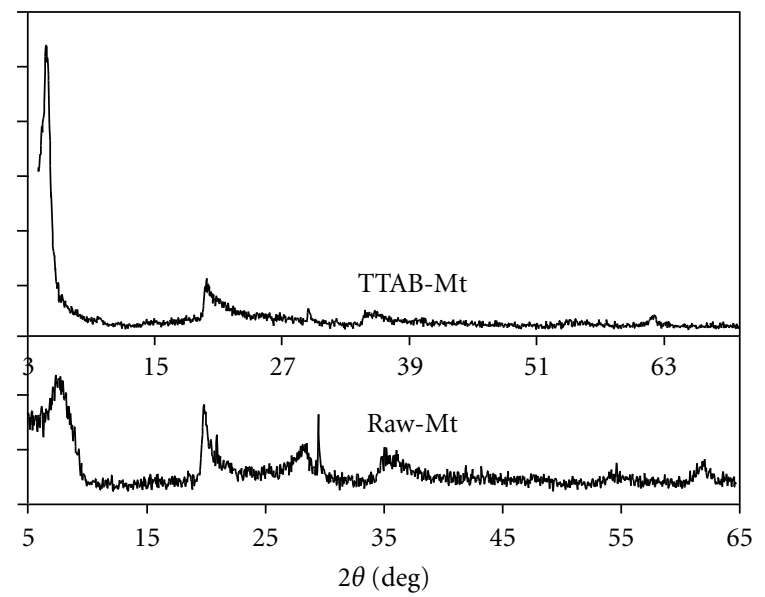

(d)

FIgURE 1: Characteristics of the adsorbent. SEM for (a) Raw-Mt and (b) TTAB-Mt. (c) FT-IR and (d) XRD of raw and modified adsorbent.

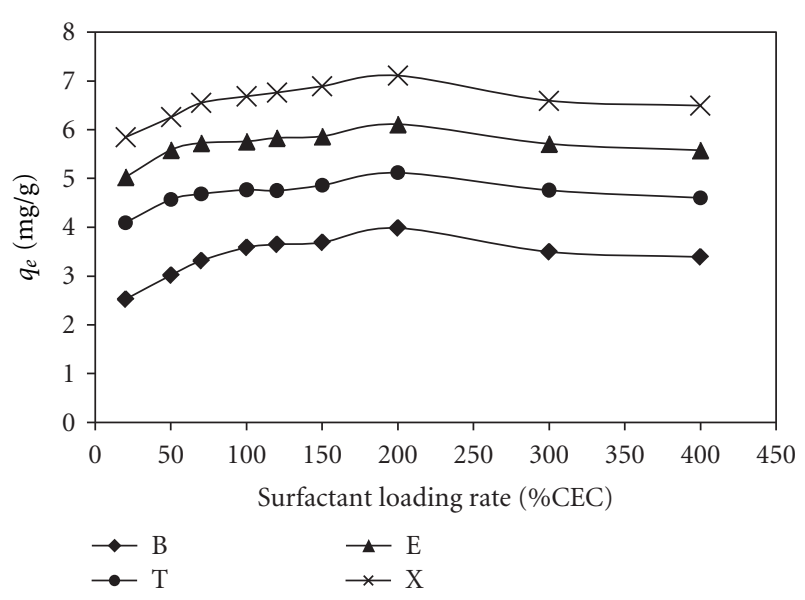

FIGURE 2: Effect of different loading rates of surfactant on adsorption of BTEX by TTAB-Mt (BTEX solution $=150 \mathrm{mg} / \mathrm{L}$, initial $\mathrm{pH}=7 \pm$ 0.5 , contact time $=24 \mathrm{~h}$, and adsorbent conc. $=5 \mathrm{~g} / \mathrm{L}$ ).

in Figure 3(a). The adsorption capacity of BTEX using modified adsorbent has been rapidly increased at the beginning of contact time which could be due to the availability of more adsorption sites [32]. Then the adsorption capacity increases slowly up to about $24 \mathrm{~h}$. The adsorption capacity of TTAB-Mt at the first hour of the adsorption was determined to be $3.06 \mathrm{mg} / \mathrm{g}, 3.24 \mathrm{mg} / \mathrm{g}, 3.71 \mathrm{mg} / \mathrm{g}$, and $4.6 \mathrm{mg} / \mathrm{g}$ for benzene, toluene, ethylbenzene, and xylene, respectively. But the corresponding adsorption capacity at the equailibrium time was estimated to be $3.98 \mathrm{mg} / \mathrm{g}, 5.15 \mathrm{mg} / \mathrm{g}, 6.0 \mathrm{mg} / \mathrm{g}$, and $6.98 \mathrm{mg} / \mathrm{g}$.

The order of the sorption capacity of the modified adsorbent is $\mathrm{B}<\mathrm{T}<\mathrm{E}<\mathrm{X}$. This order may be due to the water solubility [2], B $(1790 \mathrm{mg} / \mathrm{L})>\mathrm{T}(530 \mathrm{mg} / \mathrm{L})>\mathrm{E}$ $(152 \mathrm{mg} / \mathrm{L})>\mathrm{X}(150.5 \mathrm{mg} / \mathrm{L})$ and the corresponding nature of hydrophobicity (based on $\log k_{\mathrm{ow}}$ ) estimated as $\mathrm{B}=2.13$, $\mathrm{T}=2.69, \mathrm{E}=3.15$, and $\mathrm{X}=3.15$ [1]. Many previous studies have confirmed that the sorption of BTEX from aqueous solutions with various adsorbents follows a similar order as above $[1,2,4,8]$. Removal of BTEX by various adsorbents is presented in Table 2 . As seen, the adsorption capacity of BTEX with the modified clay in this study is higher than other clays, especially for benzene. The removal efficiency of BTEX by activated carbon (Table 2 ) is nearly equal with TTAB-clay. 


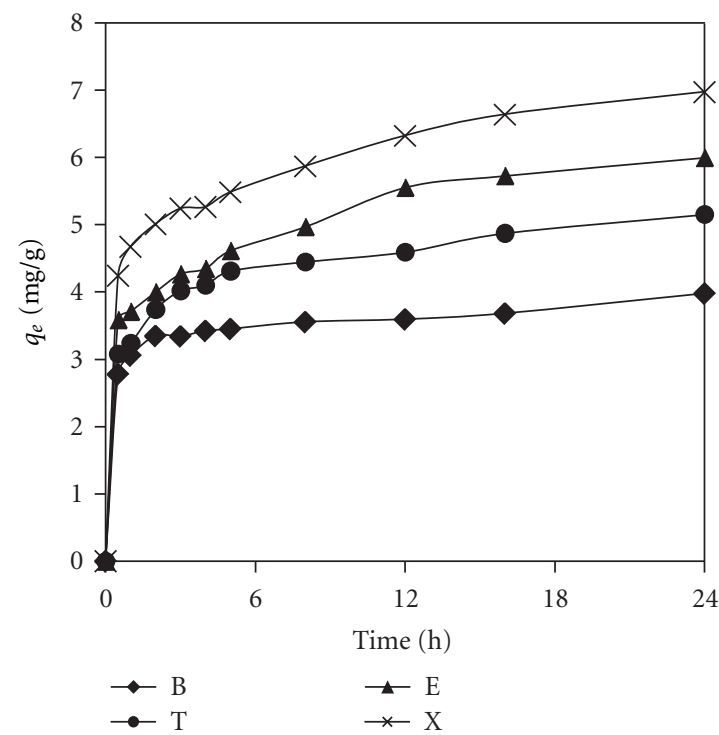

(a)

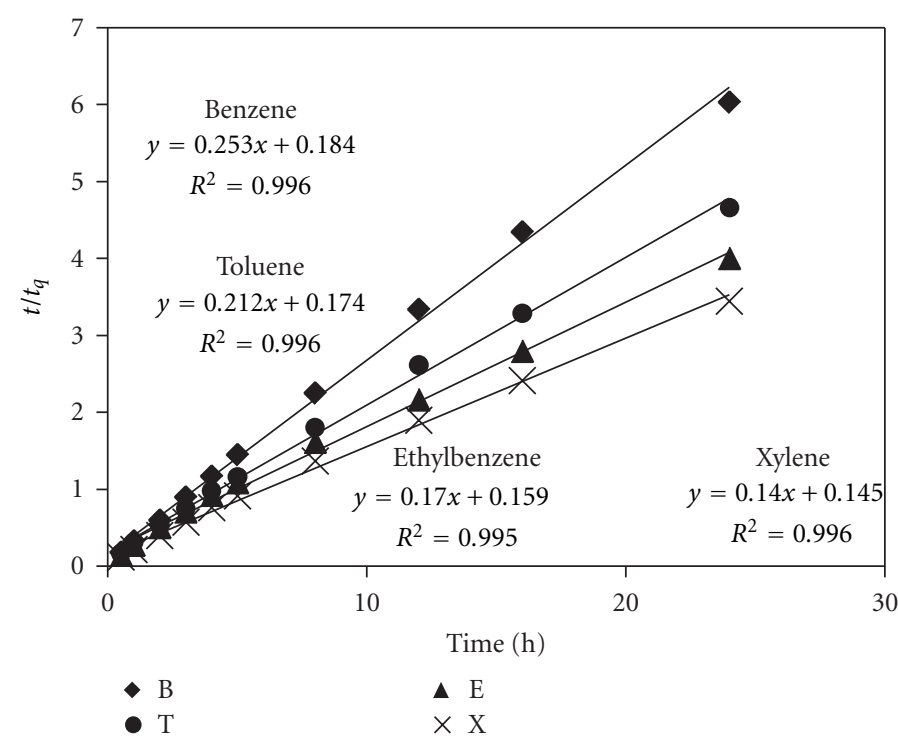

(b)

Figure 3: (a) Effects of contact time in removal of BTEX by TTAB-Mt (BTEX solution $=150 \mathrm{mg} / \mathrm{L}$, initial $\mathrm{pH}=7 \pm 0.5$, contact time $=24 \mathrm{~h}$, and organoclay conc. $=5 \mathrm{~g} / \mathrm{L}$ ), (b) pseudo-second-order model.

However the uptake efficiency for carbon nanotube (CNT$\mathrm{NaOCl}$ ) is much higher than TTAB clay. The effect of contact time on removing BTEX by the Raw-Mt (data not presented) showed that the adsorption capacity of the raw adsorbent for these compounds was 11 to 13 times less than that for TTAB-Mt. Therefore, TTAB-Mt and contact time of $24 \mathrm{~h}$ were used, respectively, as the adsorbent and optimum time for the remaining experiments.

3.3.1. Adsorption Kinetics. Adsorption kinetics is one of the most important parameters for determining the adsorption mechanism and also to investigate the efficacy of adsorbent for the removal of pollutants. In this study, three kinetic models, pseudo-first-order, pseudo-second-order, and intraparticle diffusion models, were used to predict the sorption behavior of the data.

The pseudo-first-order kinetic model [26] is defined as

$$
\ln \left(q_{e}-q_{t}\right)=\ln q_{e}-k_{1} t
$$

where $q_{e}(\mathrm{mg} / \mathrm{g})$ and $q_{t}(\mathrm{mg} / \mathrm{g})$ are the amounts of BTEX adsorbed by TTAB-Mt at equilibrium conditions and at time $(t)$, respectively. $k_{1}(1 / \mathrm{h})$ is the rate constant of pseudo-firstorder kinetic model [26]. $k_{1}$ and $q_{e}$ are determined from the slope and intercept of $\ln \left(q_{e}-q_{t}\right)$ versus $t$, respectively. The pseudo-second-order model was also fitted to the adsorption data using the following equation [33]:

$$
\frac{t}{q_{t}}=\frac{1}{k_{2} q_{e}^{2}}+\frac{t}{q_{e}}
$$

where $q_{e}$ and $q_{t}$ are the same as for the pseudo-first-order parameters. $k_{2}(\mathrm{~g} / \mathrm{mg} \cdot \mathrm{h})$ is the rate constant of pseudosecond order. In Figure 3(b), $k_{2}$ and $q_{e}$ values are obtained from the intercept and slope of linear plot of $t / q t$ against $t$, respectively [33]. At initial stage of the adsorption process $(t \sim 0)$, the initial adsorption rate, $h(\mathrm{~g} / \mathrm{mg} \cdot \mathrm{h})$, is obtained from

$$
h=k_{2} q_{e}^{2}
$$

The intraparticle diffusion kinetic model is mathematically described by the following equation [28]:

$$
q_{t}=k_{i d} t^{1 / 2}+C,
$$

where $k_{i d}(\mathrm{~g} / \mathrm{mg} \cdot \mathrm{h})$ is the rate of the intraparticle diffusion kinetic model [28]. $k_{i d}$ and $C$ are obtained from the slope and intercept of $q_{t}$ versus $t^{1 / 2}$, respectively.

Figure 3(b) shows a plot of pseudo-second-order kinetic model for the adsorption of BTEX with TTAB-Mt. As can be seen from the correlation coefficient $\left(R^{2}\right)$, the pseudo-second-order kinetic model fits to the experimental data better than the other kinetic models. Moreover, the $q_{e, \text { calculated }}(\mathrm{mg} / \mathrm{g})$ achieved using the pseudo-second-order kinetic model is rationally similar to the $q_{e \text { experimental }}(\mathrm{mg} / \mathrm{g})$ obtained from the experimental data. On the other hand, the pseudo-first-order and intraparticle diffusion models, because of the difference between calculated $q_{e}$ from the models and experimental $q_{e}$, do not suitably predict BTEX sorption by the adsorbent. Aivalioti et al. (2010 and 2011) reported that sorption of BTEX with raw and thermally modified diatomite was described well by the pseudo-secondorder kinetic model $[1,4]$. The parameters for pseudosecond-order kinetic model are listed in Table 3. As seen, the values of the rate constant for pseudo-second-order kinetic models, $k_{2}$ (g/mg.h), follow the order of $\mathrm{B}>\mathrm{T}>\mathrm{E}>$ $\mathrm{X}$, while the initial adsorption rate constant values of this kinetic model, $h(\mathrm{~g} / \mathrm{mg} \cdot \mathrm{h})$, are shown to have the order of 
TABLE 2: Removal of BTEX from aqueous solutions by various adsorbents.

\begin{tabular}{|c|c|c|c|c|c|}
\hline Adsorbent & Benzene (mg/g) & Toluene (mg/g) & Ethylbenzene (mg/g) & Xylene (mg/g) & Reference \\
\hline TMPA-clay & 1.13 & 8.65 & 3.18 & 4.24 & {$[12]$} \\
\hline Adam-clay & 0.47 & 4.32 & 1.59 & 2.44 & {$[12]$} \\
\hline HDTMA-clay & 0.47 & 6.8 & 4.24 & 7.21 & {$[12]$} \\
\hline $\mathrm{CNT}(\mathrm{NaOCl})$ & 200 & 220 & 250 & 270 & {$[2]$} \\
\hline Diatomite & 0.031 & 0.037 & 0.042 & $0.042-0.095$ & {$[4]$} \\
\hline Activated carbon & 4.5 & 5 & 6 & 6.5 & {$[8]$} \\
\hline TTAB-Clay & 3.98 & 5.15 & 6 & 6.98 & This study \\
\hline
\end{tabular}

TABLE 3: Parameters of pseudo-second order kinetic model obtained from the adsorption data.

\begin{tabular}{|c|c|c|c|c|c|}
\hline \multirow{2}{*}{ Adsorbate } & \multirow{2}{*}{$q_{e, \text { experimental }}(\mathrm{mg} / \mathrm{g})$} & \multicolumn{4}{|c|}{ Pseudo-second order } \\
\hline & & $k_{2}(\mathrm{~g} / \mathrm{mg} \cdot \mathrm{h})$ & $h(\mathrm{~g} / \mathrm{mg} \cdot \mathrm{h})$ & $q_{e, \text { calculated }}(\mathrm{mg} / \mathrm{g})$ & $R^{2}$ \\
\hline Benzene & 3.98 & 0.35 & 5.43 & 3.95 & 0.996 \\
\hline Toluene & 5.15 & 0.26 & 5.75 & 4.72 & 0.995 \\
\hline Ethylbenzene & 6.00 & 0.18 & 6.29 & 5.88 & 0.996 \\
\hline Xylene & 6.98 & 0.14 & 6.90 & 7.14 & 0.996 \\
\hline
\end{tabular}

$\mathrm{B}<\mathrm{T}<\mathrm{E}<\mathrm{X}$. The reason for this (the order of $h$ value) may be due to availability of more adsorption sites of the adsorbent at the beginning of the sorption process [32]. Hence, the lower hydrophilic compounds such as xylene and ethylbenzene have a higher tendency to the adsorbent, especially at the start of the adsorption process. But as the time elapsed, the order of $k_{2}$ value has a reverse relation with the order of $h$ value. This may be attributed to the molecular weight of BTEX. Due to lower molecular weight, benzene and then toluene can better penetrate onto the internal adsorption sites of the adsorbent as in comparison to higher-molecularweight compounds such as ethylbenzene and xylene.

3.4. Effects of $\mathrm{pH}$ and Adsorbate Concentration. The results for the effects of solution $\mathrm{pH}$ on the sorption of BTEX with TTAB-Mt are shown in Figure 4(a). It is clear that the amount of adsorbate uptake via the adsorbent slightly depends on the solution $\mathrm{pH}$ and increase of $\mathrm{pH}$ from 4 to 12 has not significantly affected BTEX adsorption by TTAB-Mt. This can be an indication of on high stability of the adsorbent over a wide range of $\mathrm{pH}$ [2]. Figure 4(b) shows the influences of initial BTEX concentrations between 10 and $200 \mathrm{mg} / \mathrm{L}$ on the sorption using TTAB-Mt at initial $\mathrm{pH}$ for $24 \mathrm{~h}$. Based on the results, the initial concentration of BTEX has substantial role on the adsorption capacity. As seen, the adsorption capacity of the sorbent was increased by increasing BTEX concentration in the solution. This may be due to an increase in driving forces affecting BTEX compounds. One of these forces is van der Waal's force that affects active adsorption sites of the adsorbent, which occurs at higher concentrations [8].

3.4.1. Adsorption Isotherms. Adsorption isotherm is one of the most important parameters to find the adsorption mechanism and necessary for designing any sorption system. Three isotherm models, Langmuir, Freundlich, and DubininRadushkevich $(D-R)$, were used to analyze the adsorbed
BTEX onto TTAB-Mt. The Langmuir isotherm model can be applied for the maximum monolayer adsorption capacity of the adsorbent [34]. This isotherm model in liner form is shown by

$$
\frac{C_{e}}{q_{e}}=\frac{C_{e}}{Q_{m}}+\frac{1}{b Q_{m}},
$$

where $C_{e}(\mathrm{mg} / \mathrm{L})$ and $q_{e}(\mathrm{mg} / \mathrm{g})$ are the concentration of adsorbate and the adsorption capacity of the adsorbent at the equilibrium time, respectively. $b(\mathrm{~L} / \mathrm{mg})$ is the Langmuir constant and $Q_{m}(\mathrm{mg} / \mathrm{g})$ is maximum adsorbent capacity [34]. $Q_{m}$ and $b$ are attained by the slope and intercept of $C_{e} / q_{e}$ versus $C_{e}$, respectively. The values of the Langmuir isotherm parameters are given in Table 4.

The Freundlich isotherm model is used for multilayer adsorption on a heterogeneous adsorbent surface [18]. The Freundlich isotherm model can be described by

$$
\ln q_{e}=\ln k_{f}+\frac{1}{n} \ln C_{e},
$$

where $K_{f}(\mathrm{~L} / \mathrm{g})$ and $n$ are the isotherm constants and indicate the capacity and intensity of the adsorption, respectively. As shown in Figure $4(\mathrm{c}), K_{f}$ and $n$ are determined from the intercept and slope of $\ln q_{e}$ versus $\ln C_{e}$, respectively [18]. The Freundlich isotherm parameters and its correlation coefficient $\left(R^{2}\right)$ are exhibited in Table 4 . The results show that Freundlich isotherm model fits well to the experimental data. Many researchers have showed that sorption of BTEX from aqueous solutions with different adsorbents is described well by Freundlich isotherm model $[1,2,7,12]$. The adsorption bond between adsorbent and adsorbate would be relatively strong if the $n$ value, obtained from Freundlich isotherm model, is greater than one [18]. Therefore, the $n$ values of 1.04 to 1.55 obtained by this isotherm model showed that BTEX is suitably adsorbed by TTAB-Mt. Sharmasarkar et al. (2000) reported that the $n$ values for the removal of BTEX via the 


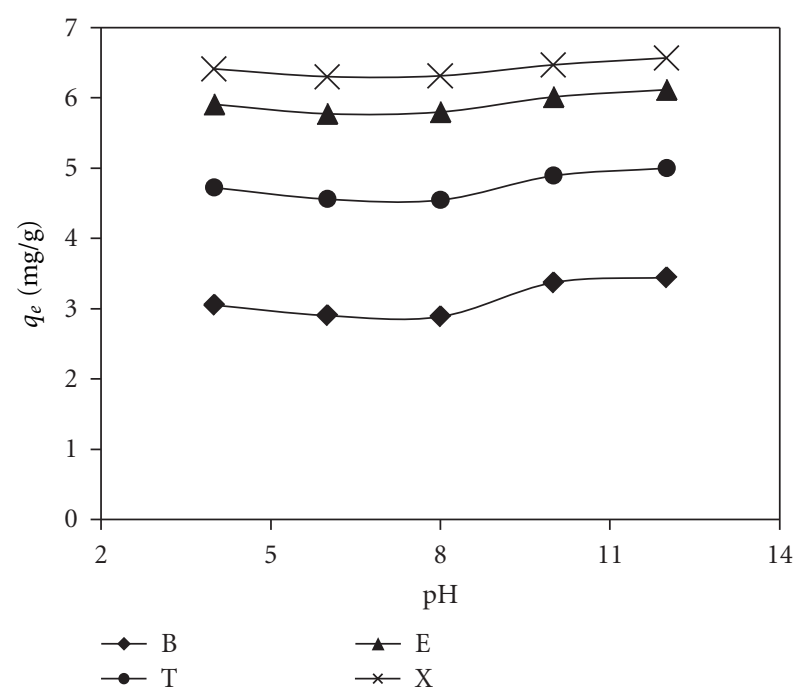

(a)

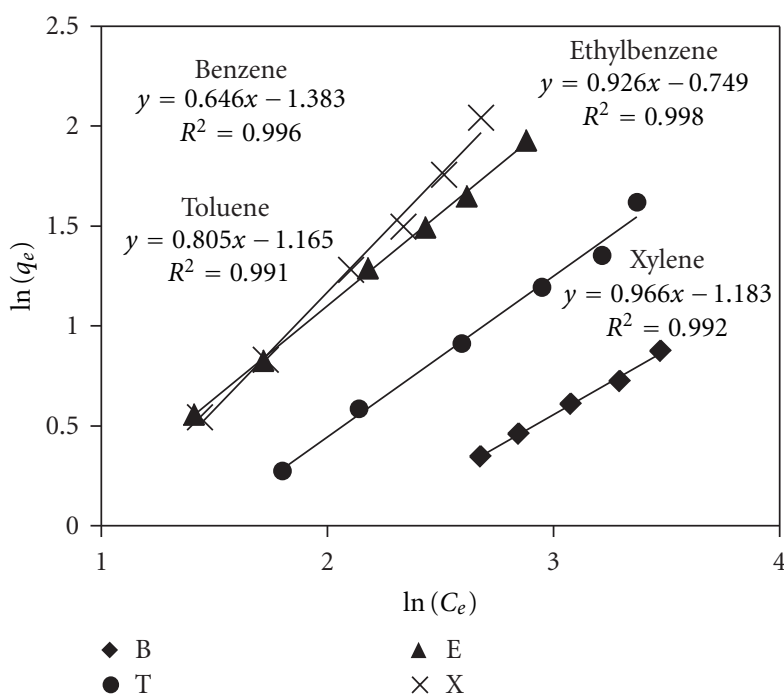

(c)

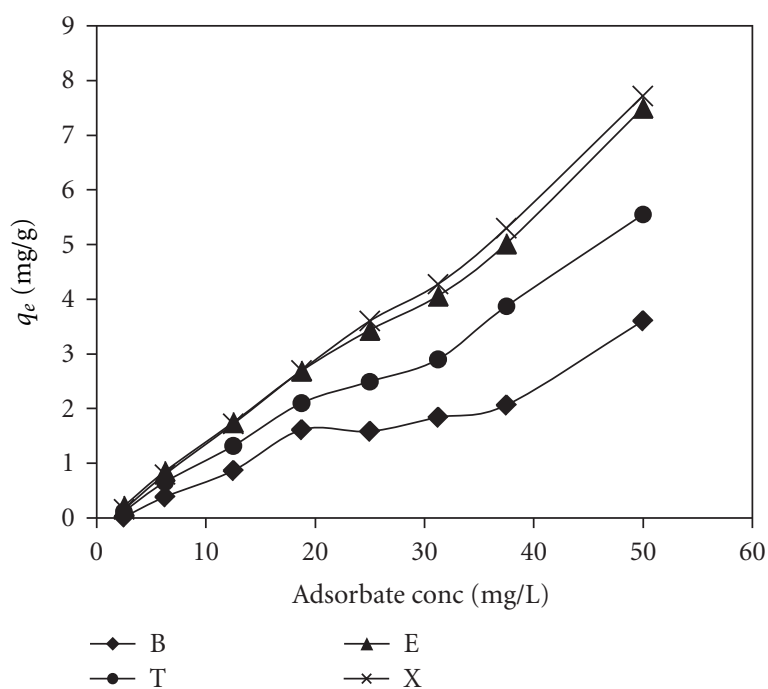

(b)

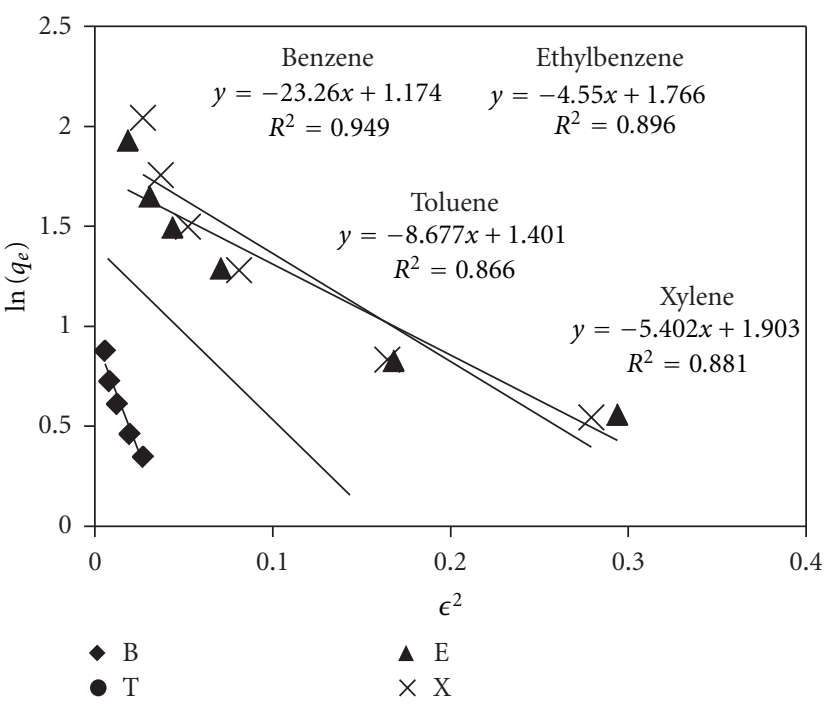

(d)

FIGURE 4: (a) Effect of $\mathrm{pH}$ on the adsorption of BTEX by the TTAB-Mt (BTEX solution $=150 \mathrm{mg} / \mathrm{L}$, contact time $=24 \mathrm{~h}$ and TTAB-Mt conc. $=5 \mathrm{~g} / \mathrm{L}$ ). (b) The effect of BTEX concentration on the adsorption by TTAB-Mt. (initial pH $=7 \pm 0.5$, contact time $=24 \mathrm{~h}$ and TTAB-Mt conc. $=5 \mathrm{~g} / \mathrm{L})$. (c) Freundlich isotherm model and (d) $D-R$ isotherm model.

cationic modified clays (TMPA-SWy and Adam-SWy) were in range of 1.59 to 1.88 [12].

The Dubinin-Radushkevich isotherm $(D-R)$ model has been used to determine the type of adsorption process as physical, chemical adsorption or ion exchange [35]. The linear form of the $D-R$ isotherm model can be shown as:

$$
\ln q_{e}=\ln q_{m}-\beta \varepsilon^{2}
$$

where, $q_{m}(\mathrm{mg} / \mathrm{g})$ is the theoretical sorption capacity based on the isotherm, $\beta(\mathrm{kJ} / \mathrm{mol})$ is related to mean adsorption energy and $\varepsilon$ (Polanyi Potential) is equal to $R T \ln (1+1 / C e)$. $R(\mathrm{~kJ} / \mathrm{mol} \cdot \mathrm{K})$ is the universal gas constant and $T(\mathrm{~K})$ is temperature [35].
Figure 4(d), $q_{m}$ and $\beta$ are obtained from the intercept and slope $\ln q_{e}$ versus $\varepsilon^{2}$, respectively. $E(\mathrm{~kJ} / \mathrm{mol})$ is the mean adsorption energy that is illustrated by equation (9):

$$
E=\frac{1}{\sqrt{2 \beta}}
$$

The type of adsorption process is specified by the $E$ value as follow: The physical and chemical adsorptions are occurred in $E<8 \mathrm{~kJ} / \mathrm{mol}$ and $E>16 \mathrm{~kJ} / \mathrm{mol}$, respectively. But the chemical ion exchange occurs for $E$ in the $8-16 \mathrm{~kJ} / \mathrm{mol}$ [36]. The values of parameters for $D-R$ isotherm model are presented in Table 4. As seen, the adsorptionof BTEX through TTAB-Mt has occurred for $E$ values in the range 
TABLE 4: Parameters for Langmuir, Freundlich, and $D-R$ isotherm models for adsorption of BTEX by TTAB-Mt.

\begin{tabular}{lccccccrrr}
\hline \multirow{2}{*}{ Adsorbate } & \multicolumn{3}{c}{ Langmuir isotherm } & \multicolumn{3}{c}{ Freundlich isotherm } & \multicolumn{3}{c}{$D-R$ isotherm } \\
& $Q_{m}(\mathrm{mg} / \mathrm{g})$ & $b(\mathrm{~L} / \mathrm{mg})$ & $R^{2}$ & $K_{f}$ & $n$ & $R^{2}$ & $q_{m}(\mathrm{mg} / \mathrm{g})$ & $E(\mathrm{~kJ} / \mathrm{mol})$ & $R^{2}$ \\
\hline Benzene & 3.61 & 0.049 & 0.971 & 0.041 & 1.55 & $\mathbf{0 . 9 9 6}$ & 3.22 & 0.147 \\
Toluene & 5.52 & 0.083 & 0.940 & 0.068 & 1.24 & $\mathbf{0 . 9 9 1}$ & 4.04 & 0.949 \\
Ethylbenzene & 6.90 & 0.201 & 0.986 & 0.160 & 1.08 & $\mathbf{0 . 9 9 8}$ & 5.82 & 0.240 & 0.866 \\
Xylene & 8.26 & 0.126 & 0.847 & 0.066 & 1.04 & $\mathbf{0 . 9 9 2}$ & 6.67 & 0.331 & 0.896 \\
\hline
\end{tabular}

TABLE 5: Thermodynamic parameters for removal of BTEX by TTAB-Mt.

\begin{tabular}{lccccccccccc}
\hline \multirow{2}{*}{ Adsorbate } & \multicolumn{9}{c}{$q_{e}(\mathrm{mg} / \mathrm{g})$} & \multicolumn{4}{c}{$\Delta G(\mathrm{~kJ} / \mathrm{mol})$} & \multicolumn{2}{c}{$\Delta H$} & \multicolumn{2}{c}{$\Delta S$} \\
& $283 \mathrm{~K}$ & $293 \mathrm{~K}$ & $303 \mathrm{~K}$ & $313 \mathrm{~K}$ & $283 \mathrm{~K}$ & $293 \mathrm{~K}$ & $303 \mathrm{~K}$ & $313 \mathrm{~K}$ & $(\mathrm{~kJ} / \mathrm{mol})$ & $(\mathrm{J} / \mathrm{mol} \cdot \mathrm{K})$ \\
\hline Benzene & 2.98 & 3.85 & 4.46 & 5.55 & -0.35 & -1.75 & -3.14 & -4.53 & 39.10 & 139.34 \\
Toluene & 4.52 & 4.88 & 5.93 & 6.87 & -1.09 & -2.21 & -3.33 & -4.45 & 30.70 & 112.24 \\
Ethylbenzene & 4.46 & 5.48 & 6.36 & 7.33 & -1.42 & -2.40 & -3.39 & -4.37 & 26.46 & 98.44 \\
Xylene & 5.55 & 6.28 & 6.80 & 7.75 & -1.63 & -2.63 & -3.62 & -4.62 & 26.50 & 99.35 \\
\hline
\end{tabular}

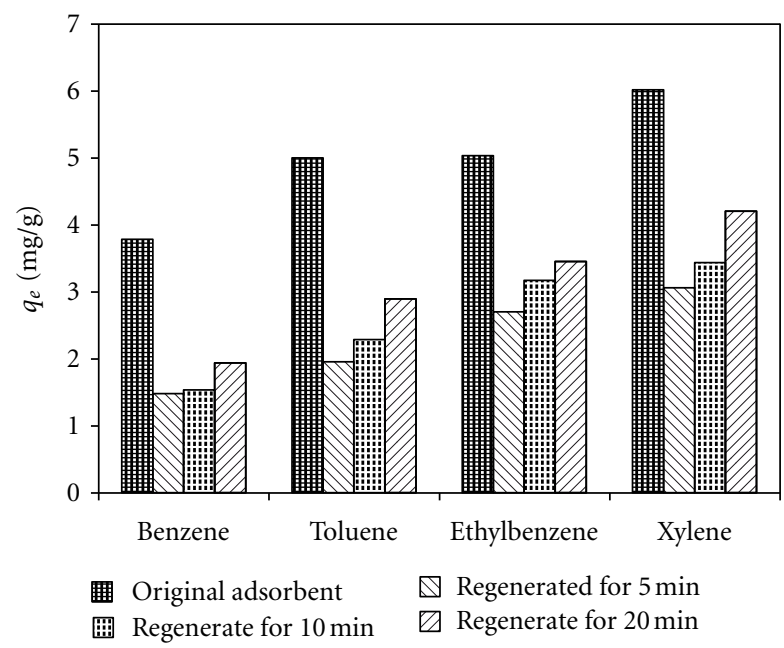

FIgURE 5: Effect of temperature of $150^{\circ} \mathrm{C}$ at various times $(5,10$ and $20 \mathrm{~min}$ ) on the regeneration of the TTAB-Mt. (BTEX solution $=150 \mathrm{mg} / \mathrm{L}$, initial $\mathrm{pH}=7 \pm 0.5$, contact time $=24 \mathrm{~h}$ and adsorbent conc. $=5 \mathrm{~g} / \mathrm{L})$.

of $0.147-0.331 \mathrm{~kJ} / \mathrm{mol}$. Hence, the removal of BTEX in the solution by TTAB-Mt is governed by the physical adsorption.

3.5. Effect of temperature. The influence of temperature on the adsorption of BTEX via TTAB-MT was assessed for temperatures vary between 10 to $40^{\circ} \mathrm{C}$. Thermodynamic equations and their parameters such as enthalpy $(\Delta H)$, Gibbs free energy $(\Delta G)$ and entropy $(\Delta S)$ are presented by equations 10 to 12 [29].

$$
\begin{gathered}
\Delta G=\Delta H-T \Delta S, \\
K=\frac{q_{e}}{C_{e}}, \\
\ln K=\frac{\Delta S}{R}-\frac{\Delta H}{R T} .
\end{gathered}
$$

$K(\mathrm{~L} / \mathrm{g}), C_{e}(\mathrm{mg} / \mathrm{L})$ and $R(8.314 \mathrm{~J} / \mathrm{mol} \cdot \mathrm{K})$ are distribution coefficient, equilibrium concentration and universal gas constant, respectively. The sorption thermodynamic parameters including entropy $(\mathrm{J} / \mathrm{k} \cdot \mathrm{mol})$ and enthalpy $(\mathrm{kJ} / \mathrm{mol})$ were obtained from the intercept and slope of plotting $\ln K$ versus $1 / T$, respectively [29]. The Gibbs free energy $(\mathrm{kJ} / \mathrm{mol})$ was also calculated from (10). The temperature effect on the adsorption is given in Table 5. The negative values of the free energy change $(-1.75$ to $-4.62 \mathrm{~kJ} / \mathrm{mol})$ for the removal of BTEX with TTAB-Mt indicate that the adsorption process is thermodynamically feasible and spontaneous [35]. The decrease in the values of $\Delta G$ at lower temperature showed that the sorption of BTEX by the adsorbent is favorable at higher temperature. As seen from Table 5, the sorption capacities of TTAB-Mt for BTEX at various temperatures also confirmed this fact. Typically, physical adsorption occurs for the value of Gibbs free energy $(\Delta G)$ in the range of -20 to $0 \mathrm{~kJ} / \mathrm{mol}$ but the values of $\Delta \mathrm{G}$ for chemical adsorption is between -400 and $-80 \mathrm{~kJ} / \mathrm{mol}$ [29]. Therefore, this indicates that the sorption of BTEX by TTAB-Mt is physical in nature. As mentioned previously, the $D-R$ isotherm model also showed that the adsorption of BTEX by TTAB-Mt is physical. A positive value for $\Delta \mathrm{H}$ value also showed that the sorption of BTEX by the adsorbent is endothermic. The positive values of $\Delta S$ may describe an increase in degree of freedom of the adsorbed species.

3.6. Regeneration on TTAB-Mt Saturated by BTEX. In this study, temperature of $150^{\circ} \mathrm{C}$ at different times $(5,10$ and $20 \mathrm{~min}$ ) was used to regenerate the BTEX saturated adsorbent. As seen from Figure 5, the adsorption capacity of the regenerated TTAB-Mt was increased by increasing the regeneration time. The ratio of the sorption capacity of the regenerated adsorbent to the original adsorbent was increased from $39-54 \%$ for regeneration time of $5 \mathrm{~min}$ and to $51-70 \%$ for regeneration time of $20 \mathrm{~min}$. The order of adsorption capacity of the regenerated TTAB-Mt, similar to that for the original adsorbent, was found to be $\mathrm{B}<\mathrm{T}<\mathrm{E}<$ $\mathrm{X}$. 


\section{Conclusion}

Montmorillonite as a type of clay was modified by tetradecyl trimethyl ammonium bromide (TTAB-Mt) to remove BTEX from aqueous media. It was found that the optimum adsorption condition takes place for the surfactant loading rate of $200 \%$ CEC at contact time of $24 \mathrm{~h}$. The pseudo-secondorder kinetic and Freundlich isotherm models, respectively, fitted to the experimental data better than other kinetic and isotherm models. Thermodynamic study also showed that the sorption of BTEX by TTAB-Mt was endothermic, spontaneous, and physical.

\section{Acknowledgment}

This study, as a part of Ph.D. thesis, was funded by the vice chancellery for research at Isfahan University of Medical Sciences, Iran (Grant no. 390073).

\section{References}

[1] M. Aivalioti, I. Vamvasakis, and E. Gidarakos, "BTEX and MTBE adsorption onto raw and thermally modified diatomite," Journal of Hazardous Materials, vol. 178, no. 1-3, pp. 136-143, 2010.

[2] F. Su, C. Lu, and S. Hu, "Adsorption of benzene, toluene, ethylbenzene and $p$-xylene by $\mathrm{NaOCl}$-oxidized carbon nanotubes," Colliod Surface A, vol. 353, no. 1, pp. 83-91, 2010.

[3] E. Aranda, E. Marco-Urrea, G. Caminal, M. E. Arias, I. GarcíaRomera, and F. Guillén, "Advanced oxidation of benzene, toluene, ethylbenzene and xylene isomers (BTEX) by Trametes versicolor," Journal of Hazardous Materials, vol. 181, no. 1-3, pp. 181-186, 2010.

[4] M. Aivalioti, P. Papoulias, A. Kousaiti, and E. Gidarakos, "Adsorption of BTEX, MTBE and TAME on natural and modified diatomite," Journal of Hazardous Materials, vol. 207-208, pp. 117-127, 2012.

[5] M. Aivalioti, D. Pothoulaki, P. Papoulias, and E. Gidarakos, "Removal of BTEX, MTBE and TAME from aqueous solutions by adsorption onto raw and thermally treated lignite," Journal of Hazardous Materials, vol. 207-208, pp. 136-146, 2012.

[6] World Health Organization, Guidelines for Drinking-Water Quality, World Health Organization, Distribution and Sales, Geneva, Switzerland, 2004.

[7] S. H. Lin and C. Y. Huang, "Adsorption of BTEX from aqueous solution by macroreticular resins," Journal of Hazardous Materials, vol. 70, no. 1-2, pp. 21-37, 1999.

[8] A. A. M. Daifullah and B. S. Girgis, "Impact of surface characteristics of activated carbon on adsorption of BTEX," Colloids and Surfaces A, vol. 214, no. 1-3, pp. 181-193, 2003.

[9] N. Wibowo, L. Setyadhi, D. Wibowo, J. Setiawan, and S. Ismadji, "Adsorption of benzene and toluene from aqueous solutions onto activated carbon and its acid and heat treated forms: influence of surface chemistry on adsorption," Journal of Hazardous Materials, vol. 146, no. 1-2, pp. 237-242, 2007.

[10] C. Lu, F. Su, and S. Hu, "Surface modification of carbon nanotubes for enhancing BTEX adsorption from aqueous solutions," Applied Surface Science, vol. 254, no. 21, pp. 7035-7041, 2008.

[11] M. M. G. R. Vianna, F. R. Valenzuela-Diaz, V. F. J. Kozievitch, J. Dweck, and P. M. Büchler, "Synthesis and characterization of modified clays as sorbents of toluene and xylene," Materials Science Forum, vol. 498-499, pp. 691-696, 2005.

[12] S. Sharmasarkar, W. F. Jaynes, and G. F. Vance, "BTEX sorption by montmorillonite organo-clays: TMPA, ADAM, HDTMA," Water, Air, and Soil Pollution, vol. 119, no. 1-4, pp. 257-273, 2000.

[13] A. Z. Redding, S. E. Burns, R. T. Upson, and E. F. Anderson, "Organoclay sorption of benzene as a function of total organic carbon content," Journal of Colloid and Interface Science, vol. 250, no. 1, pp. 261-264, 2002.

[14] W. Jaynes and G. Vance, "BTEX sorption by organo-clays: cosorptive enhancement and equivalence of interlayer complexes," Soil Science Society of America Journal, vol. 60, no. 6, pp. 1742-1749, 1996.

[15] M. M. G. Ramos Vianna, J. Dweck, V. F. J. Kozievitch, F. R. Valenzuela-Diaz, and P. M. Büchler, "Characterization and study of sorptive properties of differently prepared organoclays from a Brazilian natural bentonite," Journal of Thermal Analysis and Calorimetry, vol. 82, no. 3, pp. 595-602, 2005.

[16] S. M. Koh and J. B. Dixon, "Preparation and application of organo-minerals as sorbents of phenol, benzene and toluene," Applied Clay Science, vol. 18, no. 3-4, pp. 111-122, 2001.

[17] R. G. Zytner, "Sorption of benzene, toluene, ethylbenzene and xylenes to various media," Journal of Hazardous Materials, vol. 38, no. 1, pp. 113-126, 1994.

[18] H. Koyuncu, N. Yıldız, U. Salgın, F. Köroğlu, and A. Çalımlı, "Adsorption of $o-, m$ - and $p$-nitrophenols onto organically modified bentonites," Journal of Hazardous Materials, vol. 185, no. 2, pp. 1332-1339, 2011.

[19] B. Hu and H. Luo, "Adsorption of hexavalent chromium onto montmorillonite modified with hydroxyaluminum and cetyltrimethylammonium bromide," Applied Clay Science, vol. 257, no. 3, pp. 769-775, 2010.

[20] A. Gil, F. C. C. Assis, S. Albeniz, and S. A. Korili, "Removal of dyes from wastewaters by adsorption on pillared clays," Chemical Engineering Journal, vol. 168, no. 3, pp. 1032-1040, 2011.

[21] M. H. Karaoglu, M. Dogan, and M. Alkan, "Kinetic analysis of reactive blue 221 adsorption on kaolinite," Desalination, vol. 256, no. 1-3, pp. 154-165, 2010.

[22] T. B. Iyim and G. Güçlü, "Removal of basic dyes from aqueous solutions using natural clay," Desalination, vol. 249, no. 3, pp. 1377-1379, 2009.

[23] Q. Zhou, S. Deng, Q. Yu et al., "Sorption of perfluorooctane sulfonate on organo-montmorillonites," Chemosphere, vol. 78, no. 6, pp. 688-694, 2010.

[24] M. Sharafimasooleh, S. Bazgir, M. Tamizifar, and A. Nemati, "Adsorption of hydrocarbons on modified nanoclays," IOP Conference Series Materials Science and Engineering, vol. 18, no. 18, p. 182012, 2011.

[25] P. Baskaralingam, M. Pulikesi, D. Elango, V. Ramamurthi, and S. Sivanesan, "Adsorption of acid dye onto organobentonite," Journal of Hazardous Materials, vol. 128, no. 2-3, pp. 138-144, 2006.

[26] H. C. Trivedi, V. M. Patel, and R. D. Patel, "Adsorption of cellulose triacetate on calcium silicate," European Polymer Journal, vol. 9, no. 6, pp. 525-531, 1973.

[27] M. Do囚an, M. Alkan, and Y. Onganer, "Adsorption of methylene blue from aqueous solution onto perlite," Water, Air, and Soil Pollution, vol. 120, no. 3-4, pp. 229-248, 2000. 
[28] J. Su, H. F. Lin, Q. P. Wang, Z. M. Xie, and Z. L. Chen, "Adsorption of phenol from aqueous solutions by organomontmorillonite," Desalination, vol. 269, no. 1-3, pp. 163-169, 2011.

[29] U. F. Alkaram, A. A. Mukhlis, and A. H. Al-Dujaili, "The removal of phenol from aqueous solutions by adsorption using surfactant-modified bentonite and kaolinite," Journal of Hazardous Materials, vol. 169, no. 1-3, pp. 324-332, 2009.

[30] E. Eren, B. Afsin, and Y. Onal, "Removal of lead ions by acid activated and manganese oxide-coated bentonite," Journal of Hazardous Materials, vol. 161, no. 2-3, pp. 677-685, 2009.

[31] J. Ma, B. Cui, J. Dai, and D. Li, "Mechanism of adsorption of anionic dye from aqueous solutions onto organobentonite," Journal of Hazardous Materials, vol. 186, no. 2-3, pp. 1758-1765, 2011.

[32] M. Q. Jiang, X. Y. Jin, X. Q. Lu, and Z. L. Chen, "Adsorption of $\mathrm{Pb}(\mathrm{II}), \mathrm{Cd}(\mathrm{II}), \mathrm{Ni}(\mathrm{II})$ and $\mathrm{Cu}(\mathrm{II})$ onto natural kaolinite clay," Desalination, vol. 252, no. 1-3, pp. 33-39, 2010.

[33] Y. Ho and G. McKay, "Pseudo-second order model for sorption processes," Process Biochemistry, vol. 34, no. 5, pp. 451-465, 1999.

[34] I. Langmuir, "The adsorption of gases on plane surfaces of glass, mica and platinum," Journal of the American Chemical Society, vol. 40, no. 9, pp. 1361-1403, 1918.

[35] A. R. Kul and H. Koyuncu, "Adsorption of $\mathrm{Pb}(\mathrm{II})$ ions from aqueous solution by native and activated bentonite: kinetic, equilibrium and thermodynamic study," Journal of Hazardous Materials, vol. 179, no. 1-3, pp. 332-339, 2010.

[36] A. R. Cestari, E. F. S. Vieira, G. S. Vieira, and L. E. Almeida, "Aggregation and adsorption of reactive dyes in the presence of an anionic surfactant on mesoporous aminopropyl silica," Journal of Colloid and Interface Science, vol. 309, no. 2, pp. 402-411, 2007. 

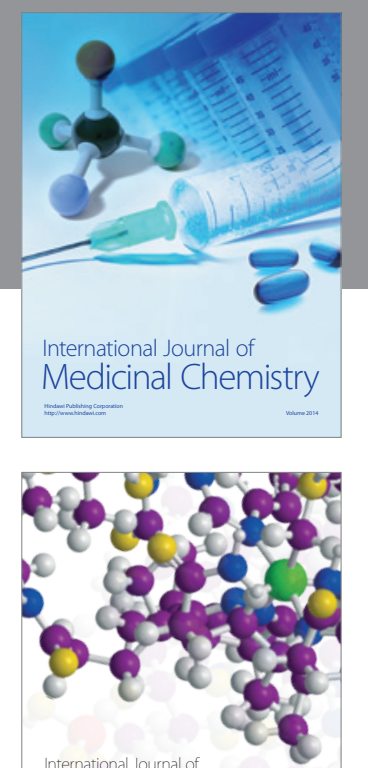

\section{Carbohydrate} Chemistry

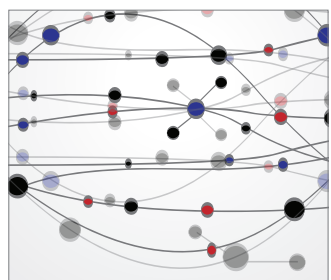

The Scientific World Journal
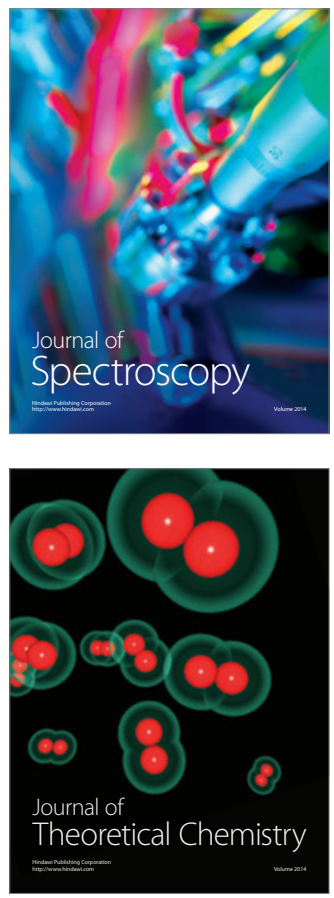
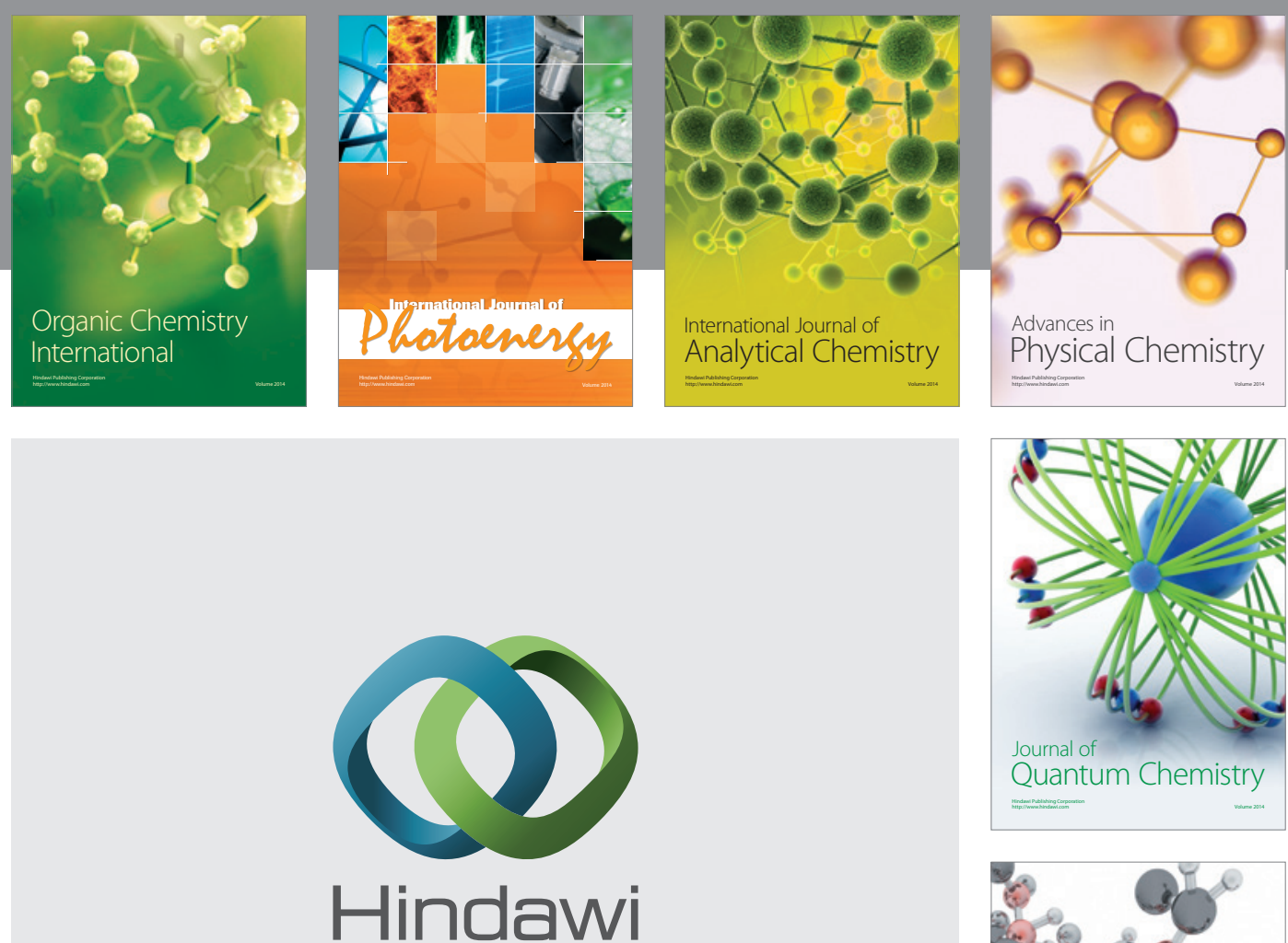

Submit your manuscripts at

http://www.hindawi.com

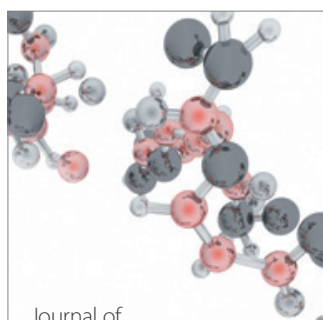

Analytical Methods

in Chemistry

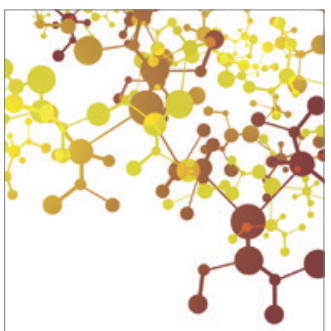

Journal of

Applied Chemistry

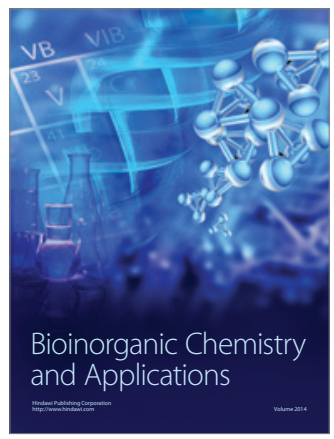

Inorganic Chemistry
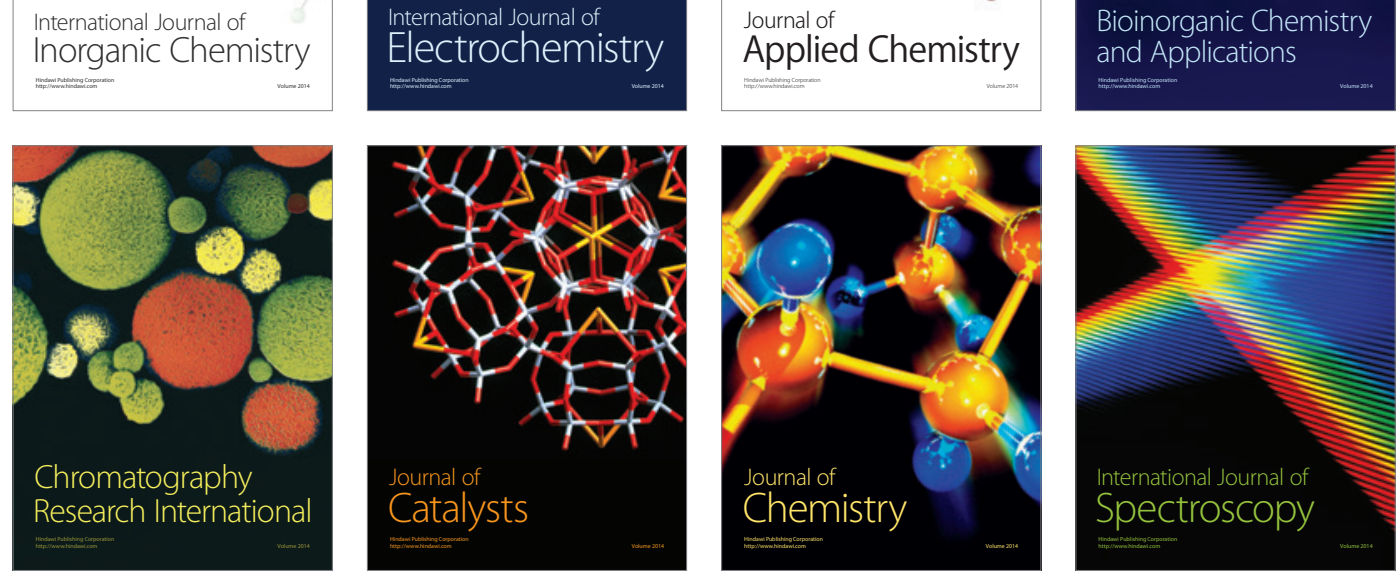